\title{
Avaliação do glicogênio hepático correlacionado com glicose sérica em ratas castradas sob tratamento com tibolona
}

Primeira submissão em 01/03/11 Última submissão em 01/03/11 Aceito para publicação em 30/05/11 Publicado em 20/10/11

\author{
Evaluation of hepatic glycogen correlated with serum glucose in castrated rats under tibolone treatment
}

Porphirio José Soares Filho'; Salim Kanaan²; Maria Angelica Guzman-Silva³

\begin{abstract}
unitermos
Tibolona

Menopausa

Glicemia

Glicogênio

Fígado

Roedores

\section{resumo}

Introdução: O glicogênio representa a forma de armazenamento de açúcares na célula animal, sendo estocada naturalmente no hepatócito. Em sua dinâmica metabólica ocorre participação de receptores, hormônios e enzimas que mantêm e equilibram os níveis séricos desse componente. Objetivo: O presente estudo investigou a influência da tibolona no metabolismo glicídico hepático por meio de avaliação da presença do glicogênio hepático e níveis séricos de glicose. Material e métodos: Utilizamos ao todo 14 ratas Wistar, em menopausa cirúrgica comprovada citologicamente, tratadas diariamente com tibolona ( $n=9)$ ou com placebo $(n=5)$ durante 20 semanas. Efetuou-se avaliação dos pesos do animal e do fígado e dos níveis de glicose sérica. O estudo morfológico foi realizado em cortes histológicos de tecido hepático, corados com hematoxilina e eosina (HE) e com ácido periódico de Schiff (PAS), com e sem amilase salivar. Para avaliação do glicogênio no fígado, utilizou-se grade de estudo morfológico (GEM), que delineia as regiões metabólicas e circulatórias do lóbulo hepático. Resultados: O peso dos animais foi menor no Grupo Tibolona, com glicose sérica em níveis mais baixos; já o peso relativo do fígado foi significativamente maior $(p<0,001)$. No Grupo Controle o glicogênio apresentou distribuição heterogênea em três diferentes padrões e o Grupo Tibolona mostrou glicogênio uniforme em toda a estrutura lobular. Conclusão: A tibolona, administrada em alta dose e por tempo prolongado, determina perda de peso por deficiência alimentar, que leva a alterações nas funções hepáticas, podendo influir na glicogenólise e na gliconeogênese, com modificações do glicogênio hepático e da glicose circulante.
\end{abstract}

abstract

Introduction: Glycogen serves as glucose storage in animals and it is naturally found in hepatocytes. Receptors, hormones and enzymes, which maintain and balance serum levels of this component, participate in its metabolic dynamics. Objective: This study investigated the influence of tibolone on the hepatic glycemic metabolism by assessing the presence of liver glycogen and serum glucose. Material and methods: Fourteen castrated Wistar rats, cytologically validated as surgical menopause models, were treated with tibolone $(\mathrm{n}=9)$ or placebo $(\mathrm{n}=5)$ for 20 weeks. Their body and liver weight and serum glucose levels were assessed. The morphologic study was performed in histological sections of liver tissue stained with hematoxylin and eosin (HE) and periodic acid-Schiff (PAS), with and without salivary amylase. For liver glycogen analysis, a morphological study grid (MSG), which outlines the metabolic and circulatory areas in the liver lobule, was applied. Results: The animals' weight was lower in the Tibolone Group, with serum glucose at lower levels, whereas the relative liver weight was significantly higher $(\mathrm{p}<0.001)$. The Control Group showed heterogeneous glycogen distribution in three different patterns. The Tibolone Group presented uniform glycogen throughout the lobular structure. Conclusion: Tibolone administration in high doses and for a long period determines weight loss by dietary deficiency, which leads to liver function changes. Thus, it may affect glycogenolysis and gluconeogenesis with changes in liver glycogen and circulating glucose. key words

Tibolone

Menopause

Blood glucose

Glycogen

Liver

Rodents

1. Mestre em Anatomia Patológica pela Universidade Federal Fluminense (UFF); professor adjunto do Departamento de Patologia da UFF.

2. Mestre em Ciências Biológicas (Biofísica) pela Universidade Federal do Rio de Janeiro (UFR)); professor adjunto do Departamento de Patologia da UFF.

3. Doutora em Patologia Experimental pela UFF; professora associada do Departamento de Patologia da UFF. 


\section{Introdução}

A terapia de reposição é um tema controverso, que apresenta resultados contraditórios e efeitos indesejáveis, os quais podem ser originados pelo seu uso prolongado ${ }^{(26)}$. Em 2002, um amplo estudo clínico chamado Iniciativa para a Saúde Feminina (WHI) confirmou que a terapia de reposição hormonal (TRH) não traz muitas vantagens para a saúde da mulher ${ }^{(21,42)}$. Outros estudos comentam o menor risco de doenças cardiovasculares e benefícios na redução da osteoporose ${ }^{(27,40)}$, entretanto, alguns trabalhos já relacionam TRH com elevação do risco de carcinoma de mama ${ }^{(16)}$, mas há discordâncias a respeito, sugerindo-se menor dosagem do estrogênio com administração cautelosa e monitorada a longo prazo ${ }^{(35)}$.

A reposição hormonal via oral obrigatoriamente passa pelo fígado, portanto, sendo um órgão de embate ao metabolismo dessa droga, pode desenvolver alterações funcionais ou estruturais ${ }^{(1)}$, motivo pelo qual se utilizam análogos aos esteroides sexuais com o objetivo de minimizar seus efeitos colaterais ${ }^{(44)}$.

A tibolona e seus metabólitos apresentam funções estrogênica, progestogênica e androgênica e é a primeira representante dos chamados reguladores de atividade estrogênica seletiva nos tecidos ${ }^{(5)}$, contudo, há controvérsias quanto possíveis alterações que essa droga possa desencadear em tecidos específicos ou mesmo no tecido hepático(1).

O presente trabalho avalia, experimentalmente, a influência da tibolona no peso corporal e sua relação com o metabolismo glicídico hepático mediante avaliação da presença de glicogênio hepático e níveis séricos de glicose.

\section{Material e métodos}

\section{Ética}

Este trabalho foi aprovado pelo Comitê de Ética em Pesquisa Animal (CEPA) $n^{\circ}$ 28/08.

\section{Animais}

Foram utilizadas 14 ratas albinas Wistar com 8 semanas de idade, peso médio de $250 \mathrm{~g}$, obtidas no Laboratório de Nutrição Experimental (LABNE) da Universidade Federal Fluminense (UFF). Os animais foram alojados em gaiolas de propileno com maravalha esterilizada. Receberam água filtrada e ração para ratos (FRI-LAB Ratos II, FRI-Ribe) fornecida ad libitum em ambiente com temperatura constante $\left(24 \pm 2^{\circ} \mathrm{C}\right)$ e iluminação em ciclos claros e escuros de 12 em 12 horas.

\section{Composto químico}

A tibolona usada foi doada pela farmácia de manipulação OFFICILAB. A droga foi dissolvida a $0,2 \%$ em solução de carboximetilcelulose (CMC) a $0,5 \%$.

\section{Procedimento cirúrgico}

A ooforectomia foi bilateral e seguiu as normas de vivisseção de animais descritas pela Sociedade Brasileira de Ciência em Animais de Laboratório (SBCAL), ex-COBEA, sob a lei $n^{\circ} 6.638$, de 8 de maio de 1979.

A anestesia foi intramuscular com quetamina $(100 \mathrm{mg} / \mathrm{kg})$ e xilazina $(20 \mathrm{mg} / \mathrm{kg})^{(24)}$. Após 30 dias da ooforectomia, o status de menopausa cirúrgica foi confirmado mediante avaliação hormonal pela citologia vaginal(3, 25), em esfregaços corados pela técnica de Papanicolau. $\mathrm{O}$ estudo citológico foi de acordo com Henriques et al. ${ }^{(15)}$ para as fases de ciclo estral e o critério adotado para a fase sem estímulo hormonal (menopausa) seguiu as descrições de Brito et al. ${ }^{(4)} \mathrm{e}$ Mendonça et al. ${ }^{(20)}$ (Tabela 1).

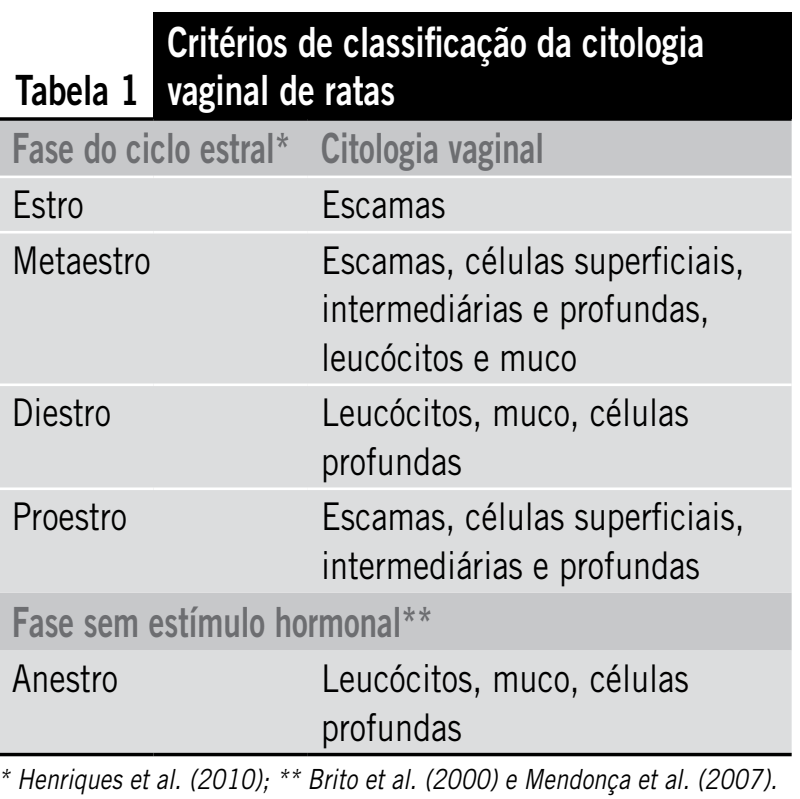

\section{Protocolo experimental}

Os animais foram divididos aleatoriamente em dois grupos: tibolona $(n=9)$ e controle $(n=5)$. As ratas foram pesadas semanalmente e o consumo de ração individual foi medido a cada três ou quatro dias, estabelecendo o consumo médio por dia ${ }^{(15)}$. 
As ratas do Grupo Tibolona receberam a droga dissolvida em CMC, por via oral, em dose de $1 \mathrm{mg} / \mathrm{dia}^{(17)}$, por um período ininterrupto de 20 semanas. Os animais do Grupo Controle receberam apenas solução de CMC $(0,5 \%)$ por gavagem. Após 20 semanas, os animais foram sedados com xilazina e quetamina. O sangue foi coletado por punção cardíaca e, a seguir, efetuou-se a eutanásia por deslocamento cervical. De cada rata foi retirado o fígado, que foi fixado em formol tamponado a $10 \%$ por 72 horas. Cada um dos quatro lobos anatômicos foi clivado e, em seguida, processado para inclusão em parafina.

\section{Estudos macroscópico e microscópico}

Os fígados foram analisados quanto a aspecto da superfície, tamanho e cor, sendo pesados em balança de precisão. Para avaliação histopatológica, foram cortados com $5 \mu \mathrm{m}$ e corados por hematoxilina e eosina (HE) e pela técnica do ácido periódico reativo de Schiff (PAS), com e sem amilase.

Para a obtenção de imagens, utilizou-se microscópio Zeiss, modelo Axioplan, sob aumento de 200x, efetuando a documentação digital no formato TIF com 14,7 MP efetivos.

\section{0 zoneamento da unidade funcional}

Foram aplicadas duas áreas triangulares (TA e TB) na imagem no Microsoft ${ }^{\circledR}$ PowerPoint, tendo como pontos de referência a veia central do lóbulo e os espaços porta, gerando um modelo de grade de estudo morfológico (GEM) com quatro áreas ou regiões por triângulo, a saber: regiões metabólicas paraportal (RePp) e paracentral (RePc), áreas sinusoidais portal (SiPo) e septal (SiSe), com total de oito na grade completa ${ }^{(33)}$ (Figura 1). A GEM foi confeccionada considerando metabolismo e circulação do fígado, de acordo com o conceito de lóbulo metabólico de Schmidt et al. ${ }^{(31)}$ e Ruijter et al.(28) e em concordância com o conceito de inflow front descrito por Masumoto et al.(18). Essa GEM é inserida na imagem microscópica mediante o programa Axiovision 4.7.2/2008.

\section{Critérios de observação morfológica}

O estudo foi efetuado à microscopia óptica com especial atenção ao componente de glicogênio, à sua distribuição e à sua relação com parte da unidade funcional hepática pela técnica do PAS, com e sem amilase salivar. A análise morfológica foi realizada nos quatro lobos hepáticos, avaliando-se presença de glicogênio por região metabólica e área circulatória ${ }^{(30,38)}$.

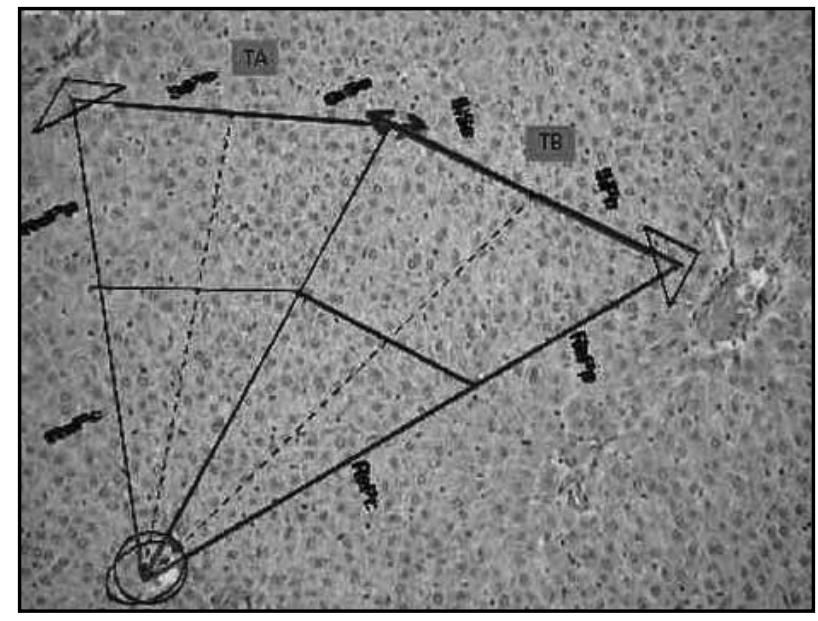

Figura 1 - Imagem no Microsoft' PowerPoint com a GEM formada por dois triângulos, $T A$ e TB, ajustados à veia centrolobular e a dois espaços porta, definindo SiPo, SiSe, RePp e RePc (HE, aumento original 200x)

GEM: grade de estudo morfológico; SiPo: área sinusoidal portal; SiSe: área sinusoidal septal; RePp: região metabólica paraportal; RePc: região metabólica paracentral; $H E$ : hematoxilina e eosina.

\section{Resultados}

\section{Peso dos animais e do fígado}

O peso corporal foi menor no Grupo Tibolona quando comparado com o do Grupo Controle e, embora não significativa, essa perda corresponde a $13 \%$. O fígado mostrava-se de volume habitual e equivalente em ambos os grupos de estudo, com elevação de peso (19\%) no Grupo Tibolona e discreta palidez. Foi observada diferença significativa (Mann-Whitney, $p<0,001)$ no peso relativo do fígado, sendo $32 \%$ maior no Grupo Tibolona (Tabela 2).

\section{Glicose sérica}

O Grupo Tibolona apresentou níveis mais baixos de glicose sérica (106-207 mg/dl), com média de $145 \mathrm{mg} / \mathrm{dl}$, quando em comparação com o Grupo Controle. Os valores neste último grupo eram mais elevados (131-250 mg/dl), com média de 173 mg/dl (Tabela 3).

\section{Glicogênio hepático}

As reações com PAS no Grupo Controle $(n=5)$ revelaram distribuição heterogênea, com intensidade variável exibindo três diferentes padrões no lóbulo hepático. Na maioria das áreas analisadas que correspondiam a $10 \mathrm{GEM}$, totalizando 80 áreas, havia distribuição difusa com hepatócitos alternadamente positivos e negativos, independente da região 


\begin{tabular}{cccc} 
Tabela 2 & \multicolumn{3}{c|}{$\begin{array}{l}\text { Peso corporal e hepático de ratas } \\
\text { castradas tratadas com tibolona }\end{array}$} \\
\hline Grupos & $\begin{array}{c}\text { Peso } \\
\text { corporal (g) }\end{array}$ & $\begin{array}{c}\text { Peso fígado } \\
(\mathrm{g})\end{array}$ & $\begin{array}{c}\text { Peso relativo } \\
\text { fígado (\%) }\end{array}$ \\
\hline Tibolona & $\begin{array}{c}214,1 \pm \\
28,4^{\mathrm{a}}\end{array}$ & $8,9 \pm 1,4^{\mathrm{a}}$ & $4,1 \pm 0,3^{\mathrm{a}}$ \\
& $\begin{array}{c}245,2^{2} \pm \\
\text { Controle }\end{array}$ & $7,5 \pm 1,2^{\mathrm{a}}$ & $3,1 \pm 0,3^{\mathrm{b}}$ \\
\hline
\end{tabular}

Letras sobrescritas diferentes na mesma coluna indicam diferença significativa. Teste Mann-Whitney ( $\mathrm{p}<0,001)$; tibolona $(\mathrm{n}=9)$; controle $(\mathrm{n}=5)$.

\begin{tabular}{ccc} 
Tabela 3 & \multicolumn{2}{c}{$\begin{array}{l}\text { Glicose sérica de ratas castradas tratadas } \\
\text { com tibolona }\end{array}$} \\
\hline Grupos & $\begin{array}{c}\text { Média e desvio } \\
\text { padrão (mg/dl) }\end{array}$ & $\begin{array}{c}\text { Amplitude } \\
\text { de valores (mg/dl) }\end{array}$ \\
\hline Tibolona & $145 \pm 35$ & $106-207$ \\
Controle & $173 \pm 53$ & $131-250$ \\
\hline
\end{tabular}

Tibolona $(n=6)$; controle $(n=4)$.

metabólica ou do padrão circulatório sinusoidal (Figura 2). Outra forma de apresentação em 6 GEM, totalizando 48 áreas, mostrou o glicogênio irregularmente distribuído em RePc e menos frequente em RePp, independente do padrão circulatório portal ou septal (Figura 3), e em 9 GEM, correspondendo a 72 áreas, a reação com o PAS ocorria predominantemente em hepatócitos de RePp e SiPo. Havia distribuição difusa com hepatócitos alternadamente positivos e negativos em RePp e SiSe. Em RePc e SiSe, a reação foi negativa (Figura 4).

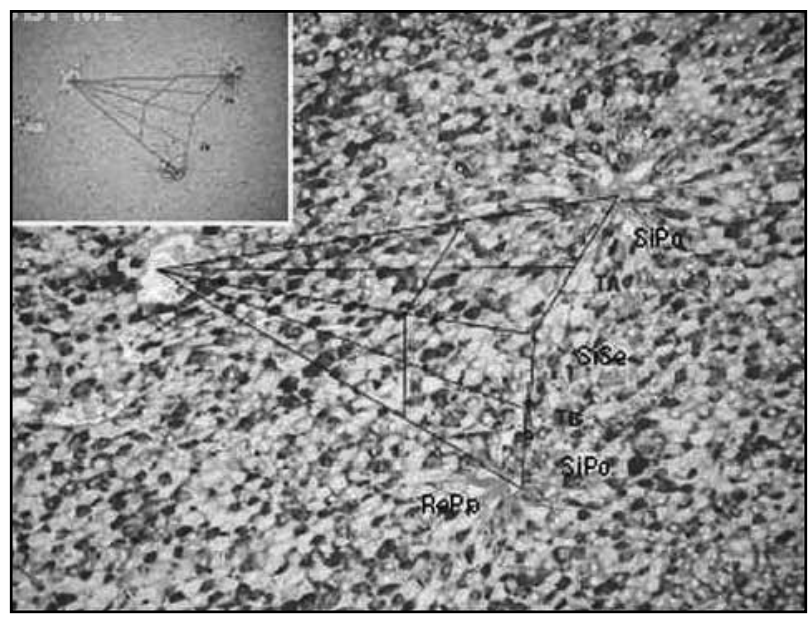

Figura 2 - Reação de PAS e PAS amilase (quadro superior) do Grupo Controle. Na GEM, glicogênio distribuído em padrão heterogêneo, independente da região metabólica ou da circulação sinusoidal (aumento original 200x)

PAS: ácido periódico de Schiff; GEM: grade de estudo morfológico.

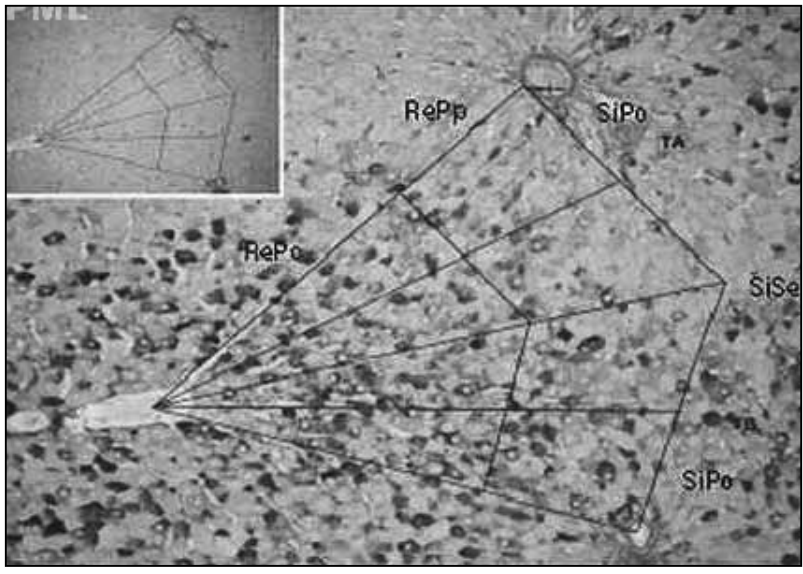

Figura 3 - Reação de PAS e PAS amilase (quadro superior) do Grupo Controle. Na GEM, em TA, glicogênio com distribuição heterogênea em RePc e menos frequente em RePp (aumento original 200x)

PAS: ácido periódico de Schiff; GEM: grade de estudo morfológico; RePc: região metabólica paracentral; RePp: região metabólica paraportal.

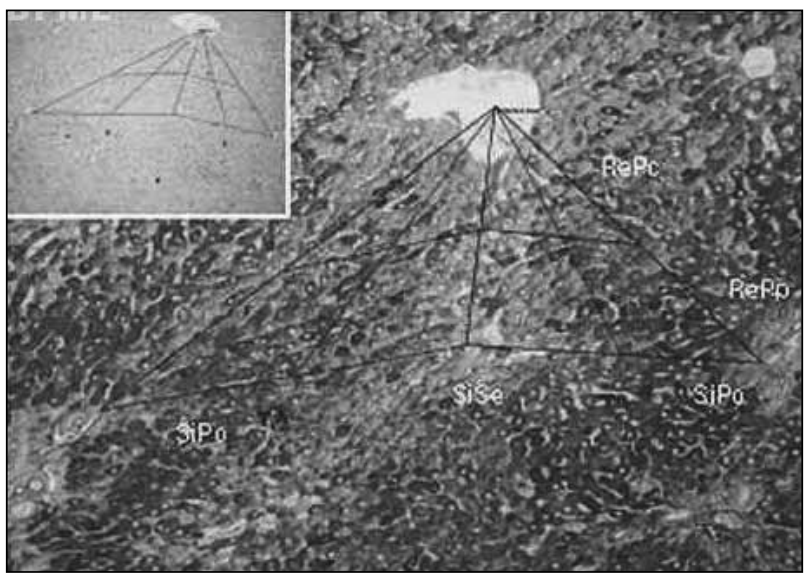

Figura 4 - Reação de PAS e PAS amilase (quadro superior) do Grupo Controle. Na GEM, glicogênio em RePp mais frequente em SiPo. Glicogênio pouco frequente nas $R e P c$ e ausente na Sise (aumento original 200x)

PAS: ácido periódico de Schiff; GEM: grade de estudo morfológico; RePp: região metabólica paraportal; SiPo: área sinusoidal portal; RePc: região metabólica paracentral; SiSe: área sinusoidal septal.

No Grupo Tibolona $(n=9)$, nas 45 GEM analisadas, totalizando 360 áreas, havia positividade para glicogênio por toda a estrutura lobular, com distribuição homogênea e intensidade de reação uniforme discretamente mais intensa em alguns hepatócitos, independente da zona metabólica RePp ou RePc ou do padrão circulatório SiPo ou SiSe. Em todos os casos desse grupo, esse padrão foi constante e por vezes associado à discreta alteração hidrópica citoplasmática, conforme Figura 5.

\section{Discussão}

\section{Tibolona: tempo e dose}

Foi administrada tibolona em alta dose durante 20 semanas, período que corresponde, aproximadamente, a 


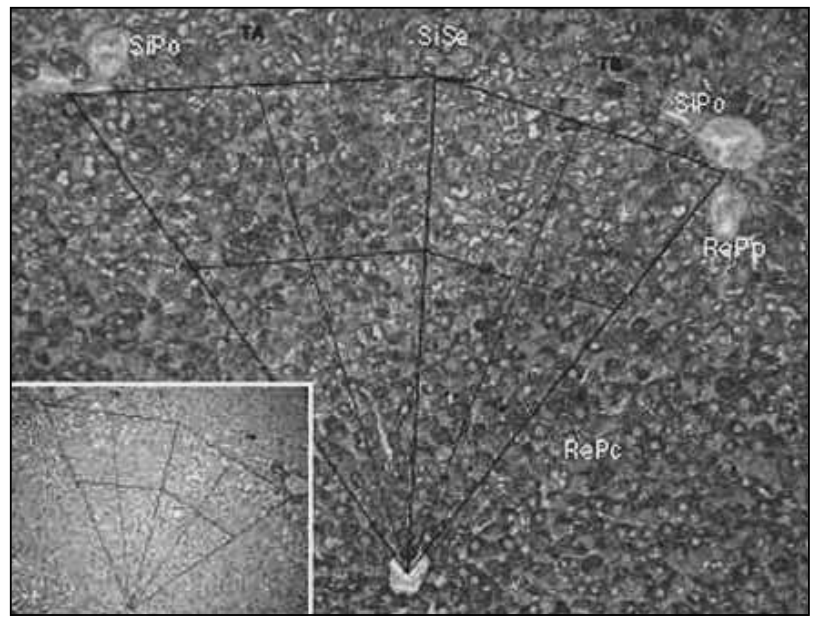

Figura 5 - Reação de PAS e PAS amilase (quadro inferior) em fígado do Grupo Tibolona. Na GEM, glicogênio uniforme em toda a grade, independente da região metabólica ou da circulação sinusoidal. Alteração hidrópica dos hepatócitos em RePp (aumento original 200x)

PAS: ácido periódico de Schiff; GEM: grade de estudo morfológico; RePp: região metabólica paraportal.

um sexto da vida do animal e mais de 10 anos em huma$\operatorname{nos}^{(6,23)}$. Em outros estudos, os períodos de administração dessa droga variam de três dias a seis semanas ${ }^{(9,10)}$. A dose empregada neste trabalho foi elevada, pois, baseada no cálculo alométrico ${ }^{(12)}$, a dose máxima preconizada em humanos equivale a $0,16137 \mathrm{mg} / \mathrm{kg}$; no presente estudo foi utilizado $1 \mathrm{mg} /$ animal pesando em média $250 \mathrm{~g}$.

\section{Peso corporal}

O menor peso corporal no Grupo Tibolona quando comparado com o Grupo Controle sugere que o tratamento com tibolona, em alta dose e por tempo prolongado, possa relacionar-se com a perda ponderal desses animais. A tibolona em ratas reduz o peso corporal devido à ação estrogênica de seus metabólitos $(\alpha / \beta-\mathrm{OH} \text {-tibolona })^{(29)}$, e de acordo com Henriques et al.(15) a perda ponderal está associada a perda de apetite e menor consumo de alimento. A perda ponderal relacionada com a diminuição na ingestão de alimentos pode ser devido a vários fatores, como variação dos níveis de triptofano, grelina ou mesmo leptina, o que, em consequência, leva a um estado de deficiência proteico calórica ${ }^{(36)}$.

Experimentalmente, está estabelecido que a tibolona exerce efeito dose-dependente que se correlaciona com o decréscimo progressivo do peso corporal em ratas, igualando-se aos efeitos obtidos experimentalmente com $17 \alpha$-metiletinilestradiol ${ }^{(11)}$. Em humanos, a administração de tibolona e estrogênio via oral pode favorecer ganho de peso corporal, diferentemente do que ocorre em ratas, ocasionando perda ponderal associada à diminuição na ingestão alimentar(37).

A pesquisa confirma o efeito estrogênico da tibolona, uma vez que o grupo de estudo submetido à influência da tibolona apresenta perda de peso quando comparado com o Grupo Controle.

\section{Desnutrição proteico calórica}

A desnutrição proteico calórica, também conhecida como proteico energética, se enquadra na situação de Kwashiorkor e, dependendo da gravidade, passa para quadro marasmático ${ }^{(32)}$. No Grupo Tibolona a perda ponderal relacionada com a redução na ingestão de alimentos mostra-se similar ao quadro de marasmo, em que há decréscimo de todos os nutrientes e calorias. Consequentemente, o indivíduo passa a consumir seus próprios tecidos como fonte de nutrientes. Ocorrem adaptações ao jejum prolongado, como a mobilização de ácidos graxos do tecido adiposo e aminoácidos do tecido muscular pela ação de somatotropina, glucagon e glicocorticoides. Há aumento da neoglicogênese hepática e as proteínas plasmáticas são mantidas entre os valores normais por meio dos aminoácidos do tecido muscular ${ }^{(32)}$.

Alterações drásticas na dieta repercutem sobre os parâmetros fisiológicos, como carência de proteínas séricas, alterações dos níveis de gordura e glice$\mathrm{mia}^{(14,36)}$. A deficiência proteica pode interferir com reações que dependam da integridade de elementos subcelulares e foi observada em crianças desnutridas, nas quais a fosforilação oxidativa está reduzida ${ }^{(2,41)}$. A relação de trifosfato de adenosina/difosfato de adenosina (ATP/ADP) quando em níveis baixos mantém os canais de $\mathrm{K}+$ abertos e os de $\mathrm{Ca}++$ fechados, impedindo a liberação de insulina citoplasmática e diminuindo sua liberação pelas células $\beta$ do pâncreas. Alterações em células $\beta$ associadas ao estado redox também podem alterar a secreção de insulina, reduzindo a fosforilação com diminuição da atividade enzimática, havendo correlação entre radicais livres e produção de insulina ${ }^{(7)}$.

Outro mecanismo para liberação de insulina tem relação com o acoplamento estímulo-secreção. A dieta hipoproteica leva a várias alterações no acoplamento do estímulo para a secreção da célula betapancreática, o que pode explicar a diminuição da insulina circulante ${ }^{(34)} \mathrm{e}$ a menor resposta na liberação de insulina por meio de conexinas, em especial a $36(\mathrm{C} \times 36)^{(8,34)}$. 


\section{Peso do fígado e glicogênio hepático}

O fígado apresentou discreto aumento de peso no Grupo Tibolona e o peso relativo foi significativamente maior nesse grupo. A presença de grande quantidade de glicogênio no tecido hepático no Grupo Tibolona pode esclarecer a elevação discreta do peso desse órgão, que associado à perda de peso corporal determina um elevado peso relativo do fígado.

Nossos resultados no Grupo Controle indicam que o metabolismo do glicogênio varia de acordo com as RePp e RePc e dependem dos padrões circulatórios sinusoidais septal e portal, mostrando que o metabolismo do glicogênio hepático é influenciado pelo septo vascular. Os resultados morfológicos pela reação com PAS mostram o glicogênio irregularmente distribuído no Grupo Controle com predomínio de um padrão salpicado de hepatócitos positivos, principalmente nas RePc, independente do padrão circulatório portal ou septal. Entretanto, em $36 \%$ dos casos desse grupo o glicogênio apresenta-se também nas RePp, com maior intensidade na área de circulação portal. Dessa forma, nos animais sem influência da tibolona, a glicogenólise ocorre de acordo com as solicitações orgânicas, atuando primeiramente nas RePp com circulação septal, nas quais predominam os processos oxidativos para obtenção de energia. Em todos os casos do Grupo Tibolona, a distribuição do glicogênio mostra-se constante e uniforme em todas as áreas analisadas, relacionando-se com a alteração hidrópica, o que contribui para maior peso absoluto e relativo do fígado. Isso indica também a influência dessa droga no metabolismo do glicogênio hepático, provavelmente por deficiência na atividade da glicose-6-fosfatase (G-6-P).

Em crianças com desnutrição calórica, observa-se que o glicogênio hepático está reduzido na maioria dos casos $^{(2)}$. Em contrapartida, a presença de glicogênio hepático ocorre exclusivamente em ratas tratadas com dieta hipoproteica(19). Há relatos de que em condição de restrição alimentar prolongada ocorre diminuição da atividade da G-6-P hepática e da concentração de glicose circulante ${ }^{(13)}$ e, além disso, a ingestão de dieta hipoproteica altera a atividade da enzima G-6-P(14). O papel dessa enzima é fundamental na última etapa de liberação da glicose pelos hepatócitos - processos de glicogenólise e gliconeogênese. Sua redução faz com que a glicose fique retida no tecido hepático e não seja liberada para a corrente sanguínea. Há vários autores que associam a redução da atividade dessa enzima à manutenção do glicogênio no tecido hepático, devido à dificuldade deste em ser liberado para a circulação(13, 14). Outros relatam que na desnutrição proteico calórica esse fenômeno não ocorre, pois os depósitos hepáticos de glicogênio são normalmente consumidos para manter os níveis glicêmicos ${ }^{(2,22)}$. De acordo com nossos resultados, o tratamento com alta dose de tibolona e por período prolongado determina a manutenção do glicogênio hepático, que pode estar relacionado com a deficiência alimentar registrada nesse experimento, com diminuição da capacidade hepática na liberação da glicose para o sangue circulante e, portanto, baixa glicemia.

\section{Glicose sérica}

Estudos envolvendo a desnutrição proteico calórica em seres humanos apontam valores normais ou reduzidos da glicose circulante em casos de marasmo e Kwashiorkor ${ }^{(43)}$. Em animais, há relatos de diminuição dos níveis de glicose sérica que sugerem a existência de fatores predisponentes por alguma deficiência no processo da gliconeogênese hepática e, para explicar os baixos níveis glicêmicos na desnutrição, tanto a absorção inadequada da glicose quanto a deficiência no processo de glicogenólise têm sido mencionadas ${ }^{(32)}$. Estudos em ratas desnutridas mostram que os níveis de glicemia oscilam de 108 a 114 mg/dl, enquanto em animais alimentados com dieta livre as taxas são mais elevadas e variam de 136 a $148 \mathrm{mg} / \mathrm{dl}^{(39)}$.

Neste trabalho, o Grupo Controle manteve estável o peso corporal e a glicemia ficou entre 131 e $250 \mathrm{mg} / \mathrm{dl}$, com média de $173 \mathrm{mg} / \mathrm{dl}$. O Grupo Tibolona, com menor ingestão alimentar, apresentou perda ponderal e níveis de glicose sérica entre 106 e 207mg/dl, com média de $145 \mathrm{mg} / \mathrm{dl}$. Esses resultados podem relacionar-se com a perda de apetite nesse grupo ${ }^{(15)}$ e a deficiência proteico calórica, causando diminuição da mobilização do glicogênio hepático e da glicemia, que poderia ser explicada por deficiência na atividade enzimática da G-6-P(14). Em humanos e roedores em estado de desnutrição, há relatos de baixos níveis de açúcar no sangue por redução na atividade da G-6-P que, embora possa estar elevada, provavelmente apresenta deficiência em sua atividade funcional ${ }^{(2,14)}$. Essa enzima, por sua vez, age na última etapa da liberação da glicose pelo fígado, durante a glicogenólise ou na gliconeogênese. Assim, ao reduzir a atividade dessa enzima, a glicose ficaria retida no tecido hepático e não seria liberada na corrente sanguínea ${ }^{(14)}$.

Concluímos que, devido à redução da ingestão de alimentos que leva a um quadro de deficiência proteico 
calórica, o tratamento com tibolona em alta dose e por tempo prolongado pode interferir na atividade de enzimas que participam da glicogenólise, mantendo o glicogênio hepático e os níveis baixos de glicemia.

\section{Agradecimentos}

Agradecemos o apoio da farmácia de manipulação OFFICILAB, que gentilmente forneceu a tibolona.

\section{Referências}

1. ALLEN, N. E. et al. Menopausal hormone therapy and risk of endometrial carcinoma among postmenopausal women in the European prospective investigation into cancer and nutrition. Am J Epidemiol, v. 12, n. 172, p. 1394-403, 2010.

2. ALLEYNE, G. A. O.; SCULLARD, G. H. Alterations in carbohydrate metabolism in Jamaican children with severe malnutrition. Clin Sci, n. 37, p. 631-42, 1969.

3. BIONDO-SIMÕES, M. L. P. et al. Efeitos da terapia de reposição hormonal na cicatrização de anastomoses de cólon. Acta Cir Bras, v. 3, n. 20, p. 237-40, 2005.

4. BRITO, N. M. B.; LAMARÃO, L. G.; DAMOUS, S. H. Estudo colpocitológico de ratas ooforectomozadas. Rev Para Med, v. 3, n. 14, p. 25-8, 2000.

5. BRUCE, D.; ROBINSON, J.; RYMER, J. Long term effects of tibolone on the endometrium as assessed by bleeding episodes, transvaginal scan and endometrial biopsy. Climacteric, v. 3, n. 7, p. 261-6, 2004.

6. CAMPBELL, S. J. et al. Loss of the atypical inflammatory response in juvenile and aged rats. Neuropathol Appl Neurobiol, v. 1, n. 33, p. 108-20, 2007.

7. CAPPELLI, A. P. G. Modulação da secreção de insulina por estresse oxidativo induzido em ilhotas pancreáticas de animais submetidos à desnutrição protéica. 2009. Dissertação (Mestrado) - Ciências Biológicas, Universidade Estadual de Campinas, São Paulo, 2009.

8. CARVALHO, L. A. R. et al. Co-expression and regulation of conexins 36 and 43 in cultured neonatal rat pancreatic islets. Can J Pathol Pharmacol, v. 83, n. 2, p. 142-51, 2005.

9. CZERNY, B. et al. Effect of tibolone on turnover of cholesterol to bile acids in ovariectomized rats. Menopause, v. 5, n. 12, p. 609-12, 2005.

10. DE GOOYER, M. E. et al. Tibolone is not converted by human aromatase to 7alpha-methyl-17alphaethynylestradiol (7alpha-MEE): analyses with sensitive bioassays for estrogens and androgens and with LCMSMS. Steroids, v. 3, n. 68, p. 235-43, 2003.

11. EDERVEEN, A. G. H.; KLOOSTERBOER, H. J. Tibolone, a steroid with a tissue-specific hormonal profile, completely prevents ovariectomy-induced bone loss in sexually mature rats. J Bone Miner Res, v. 11, n. 14, p. 1963-70, 1999.

12. FELIPPE, P. A. N. Sistema alométrico ou cálculo de dosagem por taxa metabólica do animal. Campinas, Unicamp. Disponível em: <http://www.ib.unicamp. br/ceea/files/ceea/calculo.doc.>. Acesso em: 10 ago. 2008.

13. FLETCHER, K. Observations on the origin of liver fat in infantile malnutrition. Am Clin Nutr, v. 2, n. 19, p. 170-4, 1996.
14. GOBATTO, C. A. Alterações metabólicas do treinamento físico em ratos previamente desnutridos e recuperados. 1993. Dissertação (Mestrado) - Ciências Biológicas, Universidade Estadual de Campinas, São Paulo, 1993.

15. HENRIQUES, H. N. et al. Efeito de doses elevadas de tibolona sobre o peso corporal e perfil lipídico de ratas ooforectomizadas. RBGO, v. 2, n. 32, p. 88-92, 2010.

16. HOLBERG, L.; ANDERSON, J. H. HABITS (hormonal replacement therapy after breast cancer - is it safe?), a randomised comparison: trial stopped. Lancet, v. 363, p. 453-5, 2004.

17. KUSCU, N. K. et al. The effect of tibolone on endometrial IGF-1 and IGFBP-1 levels in ovariectomized rats. Maturitas, n. 42. p. 247-52, 2002.

18. MATSUMOTO, T. et al. A study on the normal structure of the human liver, with special reference to its angioarchitecture. Jikeikai Med J, n. 26, p. 1-40, 1979.

19. MELLO, M. A. R.; CURRY, L.; VALLE, L. B. S. Pregnancy in young rats: effect of malnutrition. Nutr Rep Int, v. 1, n. 36, p. 527-35, 1987.

20. MENDONÇA, F. S. etal. Aspectos citopatológicos da mucosa vaginal de camundongas tratadas com progesterona. Ciênc Anim Bras, v. 2, n. 8, p. 313-8, 2007.

21. MODELSKA, K. et al. Tibolone for the post menopausal women: systematic review of randomizad trials. J Clin Endocinol Metab, n. 87, p. 16-23, 2002.

22. NEIVA, C. M.; GUERINO, M. R.; MELLO, M. A. R. Análise dos efeitos da desnutrição protéico-calórica sobre as respostas ao exercício agudo (single section) parâmetros metabólicos. Motriz, v. 1, n. 1, p. 32- 43, 1999.

23. PANTALEÃO, J. A. S. et al. Efeito da tibolona sobre o endométrio de ratas castradas. Rev Bras Ginecol Obstet, v. 3, n. 31, p. 124-30, 2009.

24. PIOVESAN, A. C. et al. Estudo morfológico e molecular da mama das ratas castradas tratadas com isoflavona ou estrogênio. Rev Bras Ginecol Obstet, v. 4, n. 27, p. 2004-9, 2005.

25. POMPEI, L. M. et al. Morphometric evaluation of effects of two sex steroids on mammary gland of female rats. Maturitas, n. 51, p. 370-9, 2005.

26. ROSSOUW, J. E.; ANDERSON, G. L.; PRENTICE, R. L. Risks and benefits of estrogen plus progestin in health postmenopausal women: principal results from the Women's Health Initiative randomized controlled trial. JAMA, n. 288, p. 321-33, 2002.

27. ROSSOUW, J. E.; PRENTICE, R. L.; MANSON, J. E. Postmenopausal hormone therapy and risk of cardiovascular disease by age and years since menopause. JAMA, n. 297, p. 1465-77, 2007. 
28. RUIJTER, J. M. et al. Relative distance: the key of the shape of hepatic building blocks. Image Anal Stereol, n. 19, p. 19-24, 2000.

29. RYMER, J. et al. Effects of tibolone on serum concentrations of lipoprotein (a) in postmenopausal women. Eur Soc Endocrinol, v. 3, n. 128, p. 259-62, 1993.

30. SAXENA, R. et al. Microanatomy of the human liver exploring the hidden interfaces. Hepatology, v. 6, n. 30, p. 1339-46, 1999.

31. SCHMIDT, T. et al. Lobular distribution pattern of lactate dehydrogenase and 6-phosphogluconate dehydrogenase activity in rat liver. Acta Histochem, n. 102, p. 37-47, 2000.

32. SILVA, P. M. et al. Efeitos da desnutrição intra-uterina e da recuperação nutricional sobre respostas metabólicas ao exercício crônico em ratos jovens. MOTRIZ, v. 2, n. 5, p. 152-8, 1999.

33. SOARES FILHO, P. J.; CARVALHO, A. C. G.; GUZMANSILVA, M. A. Mapping the functional liver unit: a tool to aid diagnosis and research. Diag Pathol (submitted), 2010.

34. SORIANO, S. et al. Reduced insulin secretion in protein malnourished mice is associated with multiple changes in the beta-cell stimulus-secretion coupling. Endocrinology, n. 151, p. 3543-54, 2010.

35. SPEROFF, L. The future of postmenopausal hormone therapy: it's time to move forward. Maturitas, v. 57, p. 103-6, 2007.
36. TACKMAN, J. M.; TEWS, J. K.; HARPER, A. E. Dietary disproportions of amino acids in the rat: effects on food intake, plasma and brain amino acids and brain serotonin. J Nutr, n. 120, p. 521-33, 1990.

37. TAX, L.; GOORISSEN, E. M.; KIVOVIC, P. M. Clinical profile of Org OD 14. Maturitas, Suppl 1, p. 3-13, 1987.

38. TEUTSCH, H. E. Distribution of 3-hydroxybutyrate dehydrogenase in primary lobules of rat liver. J Histochem Cytochem, v. 2, n. 40, p. 213-9, 1992.

39. THRALL, M. A. Bioquímica clínica de mamíferos não domésticos, aves, répteis e anfíbios comuns. In: THRALL, M. A hematologia e bioquímica clínica veterinária. São Paulo: Roca, 2007. p. 415-35.

40. WARREN, M. P. Hormone therapy for menopausal symptoms: putting benefits and risks into perspective. J Fam Pract, v. 59, n. 12, p. 1-7, 2010.

41. WATERLOW, J. C. Enzyme changes in malnutrition. J Clin Pathol, n. 4, p. 75-9, 1970.

42. WOMEN'S HEALTH INITIATIVE (WHI). Risks and benefits of estrogen plus progestin in healthy postmenopausal women: principle results from the Women's Health Initiative randomized controlled trial. JAMA, n. 288, p. 321-33, 2002.

43. WHITEHEAD, R. G.; HARLAND, P. S. Blood glucose, lactate and pyruvate in kwashiorkor. Br J Nutr, v. 4, n. 20, p. 825-31, 1966.

44. ZIMMERMAN, H. J.; LEWIS, J. H. Drug-induced cholestasis. Med Toxicol, n. 2, p. 112-60, 1987. 